\title{
Bilateral Vestibular Hypofunction: Insights in Etiologies, Clinical Subtypes, and Diagnostics
}

\author{
F. Lucieer ${ }^{1}$, P. Vonk ${ }^{2}$, N. Guinand ${ }^{3}$, R. Stokroos ${ }^{1}$, H. Kingma ${ }^{1,4}$ and \\ Raymond van de Berg ${ }^{1,4 *}$
}

\begin{abstract}
${ }^{1}$ Department of Otorhinolaryngology and Head and Neck Surgery, Division of Balance Disorders, Faculty of Health Medicine and Life Sciences, Maastricht University Medical Center, School for Mental Health and Neuroscience, Maastricht, Netherlands, ${ }^{2}$ Faculty of Health, Medicine and life Sciences, University of Maastricht, Maastricht, Netherlands, ${ }^{3}$ Service of Otorhinolaryngology and Head and Neck Surgery, Department of Clinical Neurosciences, Geneva University Hospitals,

Geneva, Switzerland, ${ }^{4}$ Faculty of Physics, Tomsk State Research University, Tomsk, Russian Federation
\end{abstract}

\section{OPEN ACCESS}

Edited by:

Sergio Carmona,

Instituto de Neurociencias de Buenos

Aires (INEBA), Argentina

Reviewed by:

Dario Andres Yacovino,

Centro Neurológico-Hospital

Francés, Argentina

Toshihisa Murofushi,

Teikyo University School of Medicine Mizonokuchi Hospital, Japan

*Correspondence:

Raymond van de Berg raymond.vande.berg@mumc.nl

Specialty section: This article was submitted to Neuro-otology,

a section of the journal

Frontiers in Neurology

Received: 03 December 2015 Accepted: 19 February 2016 Published: 04 March 2016

Citation:

Lucieer F, Vonk P, Guinand N, Stokroos $\mathrm{R}$, Kingma $\mathrm{H}$ and van de Berg R (2016) Bilateral Vestibular Hypofunction: Insights in Etiologies, Clinical Subtypes, and Diagnostics.

Front. Neurol. 7:26. doi: 10.3389/fneur.2016.00026
Objective: To evaluate the different etiologies and clinical subtypes of bilateral vestibular hypofunction $(\mathrm{BVH})$ and the value of diagnostic tools in the diagnostic process of $\mathrm{BVH}$.

Materials and methods: A retrospective case review was performed on 154 patients diagnosed with BVH in a tertiary referral center, between 2013 and 2015. Inclusion criteria comprised (1) imbalance and/or oscillopsia during locomotion and (2) summated slow phase velocity of nystagmus of less than $20 \%$ s during bithermal caloric tests.

Results: The definite etiology of BVH was determined in $47 \%$ of the cases and the probable etiology in $22 \%$. In $31 \%$, the etiology of $\mathrm{BVH}$ remained idiopathic. BVH resulted from more than 20 different etiologies. In the idiopathic group, the percentage of migraine was significantly higher compared to the non-idiopathic group (50 versus $11 \%$, $p<0.001)$. Among all patients, $23.4 \%$ were known with autoimmune disorders in their medical history. All four clinical subtypes (recurrent vertigo with $\mathrm{BVH}$, rapidly progressive $\mathrm{BVH}$, slowly progressive BVH, and slowly progressive BVH with ataxia) were found in this population. Slowly progressive BVH with ataxia comprised only $4.5 \%$ of the cases. The head impulse test was abnormal in $94 \%$ of the cases. The torsion swing test was abnormal in $66 \%$. Bilateral normal hearing to moderate hearing loss was found in $49 \%$. Blood tests did not often contribute to the determination of the etiology of the disease. Abnormal cerebral imaging was found in 21 patients.

Conclusion: $\mathrm{BVH}$ is a heterogeneous condition with various etiologies and clinical characteristics. Migraine seems to play a significant role in idiopathic BVH and autoimmunity could be a modulating factor in the development of $\mathrm{BVH}$. The distribution of etiologies of $\mathrm{BVH}$ probably depends on the clinical setting. In the diagnostic process of $\mathrm{BVH}$, the routine use of some blood tests can be reconsidered and a low-threshold use of audiometry and cerebral imaging is advised. The torsion swing test is not the "gold standard" for diagnosing BVH due to its lack of sensitivity. Future diagnostic criteria of BVH should consist of standardized vestibular tests combined with a history that is congruent with the vestibular findings.

Keywords: bilateral vestibulopathy, bilateral vestibular hypofunction, bilateral vestibular areflexia, bilateral vestibular loss, etiology, caloric tests, head impulse test, vestibular migraine 


\section{INTRODUCTION}

Bilateral vestibular hypofunction (BVH) is a heterogeneous chronic condition characterized by a bilateral reduced or absent function of the vestibular organs, the vestibular nerves or a combination of both (1-3). Patients can report a variety of symptoms, such as oscillopsia, imbalance, visual vertigo, cognitive deficits, autonomic symptoms, and impaired spatial orientation. Depending on the etiology, neurological symptoms can also be present (e.g., ataxia), as well as auditory symptoms, such as hearing loss or tinnitus (4-7). BVH is an uncommon disorder and the estimated prevalence in 2008 was 28 per 100,000 US adults (8). The impact is still controversial and not always recognized. However, increasing evidence shows that BVH causes a high decrease in quality of life and imposes a high socio-economic burden due to work-related disabilities $(9,10)$.

Diagnosing BVH can be difficult and, therefore, BVH is often under- or misdiagnosed. Many challenges are met when establishing the diagnosis of BVH. Currently, many different diagnostic tests are used for vestibular evaluation, such as the caloric test, rotatory chair tests, (video) head impulse test (HIT), vestibular-evoked myogenic potentials (VEMP), dynamic visual acuity test (DVA), etc. $(1,4,7)$. However, at this moment, no diagnostic standards regarding interpretation and implementation of vestibular test are available (7).

When the diagnosis of BVH is established in a patient, identifying the etiology still remains challenging. Previous studies showed that in $49-80 \%$ a definite or probable etiology could be defined, indicating that in $20-51 \%$ the etiology remained idiopathic $(5,11)$. The already identified etiologies of BVH vary tremendously (Table 1) (3, 12-27). The possible underlying causes of idiopathic BVH are still controversial. Studies suggest that migraine might play an important role and the prevalence of migraine has been shown to be higher in unclassified or idiopathic vertigo $(28,29)$. Furthermore, vestibular migraine is increasingly recognized as a cause of episodic vertigo (30). However, the relation between migraine and vertigo is not always recognized in clinical settings, since vertigo can precede headache, but may also begin with headache or appear later in the headache phase (28).

The variety in etiology of BVH is also reflected by different clinical manifestations of the disease. Currently, four different clinical subtypes have been described as follows: (1) recurrent vertigo and $\mathrm{BVH}$ : this clinical subtype is characterized by episodes of vertigo, followed by the development of symptoms of bilateral vestibular function loss. (2) Rapidly progressive BVH: patients experience a sudden onset or rapid progression in the course of BVH. (3) Slowly progressive BVH: the clinical symptoms of BVH develop gradually, mostly without episodes of vertigo. (4) BVH with neurological deficits: the clinical symptoms of BVH are combined with neurological deficits, such as peripheral polyneuropathy and/or cerebellar ataxia $(4,31)$.

Next to vestibular tests, many other tests, such as cerebral imaging, audiometry, and blood tests, can be used (on indication) in the diagnostic process. These tests do not evaluate the vestibular function and are mainly used to determine the etiology of BVH or coexisting problems (31). It is not yet established which tests should be part of the routine diagnostic work-up of BVH.
TABLE 1 | Etiologies of BVH $(3,31-33)$.

\begin{tabular}{|c|c|}
\hline \multicolumn{2}{|l|}{ Idiopathic (51\%) } \\
\hline $\begin{array}{l}\text { Toxic/metabolic } \\
(13-21 \%)\end{array}$ & $\begin{array}{l}\text { Antibiotics, furosemide, cisplatin, aspirin, alcohol, } \\
\text { vitamine-B12 deficiency, folate deficiency, hypothyroidism, } \\
\text { styrene poisoning, combination non-steroidal anti } \\
\text { inflammatory drug + penicillin }\end{array}$ \\
\hline $\begin{array}{l}\text { Infectious } \\
(3.8-12 \%)\end{array}$ & $\begin{array}{l}\text { Meningitis/encephalitis/cerebellitis, Lues, Behçet, Borrelia, } \\
\text { Herpes Simplex Virus, bilateral neuritis }\end{array}$ \\
\hline $\begin{array}{l}\text { Autoimmune } \\
(10 \%)\end{array}$ & $\begin{array}{l}\text { Cogan, Susac, Sarcoïdosis, Wegener's, Sjögren, colitis, } \\
\text { celiac disease, polyarteritis nodosa, antiphospholipid } \\
\text { syndrome, other systemic diseases }\end{array}$ \\
\hline Neurodegenerative & $\begin{array}{l}\text { CANVAS, superficial siderosis, episodic ataxia, multiple } \\
\text { system atrophy, polyneuropathy, SCA3, SCA6, hereditary } \\
\text { sensoric and autonomic neuropathy type IV, other ataxias }\end{array}$ \\
\hline Genetic & $\begin{array}{l}\text { DFNA9, DFNA11, DFNA15, DFNB4, mutation } \\
\text { chromosome 5q, 6q, 11q, 22q Muckle Wells (NLPR3) }\end{array}$ \\
\hline Vascular & $\begin{array}{l}\text { Supra- or infratentorial lesions, vertebrobasilar } \\
\text { dolichoectasia }\end{array}$ \\
\hline Neoplastic & $\begin{array}{l}\text { Bilateral vestibular schwannoma, Neurofibromatosis type } \\
2 \text {, metastasis lymphoma, malignant tumor }\end{array}$ \\
\hline Trauma & Head trauma, iatrogenic (e.g., bilateral Cl-implantation) \\
\hline $\begin{array}{l}\text { Other ear } \\
\text { pathology }\end{array}$ & $\begin{array}{l}\text { Bilateral Ménière's disease, otosclerosis, bilateral } \\
\text { labyrinthitis, cholesteatoma }\end{array}$ \\
\hline $\begin{array}{l}\text { Congenital/ } \\
\text { syndromal }\end{array}$ & $\begin{array}{l}\text { e.g., CHARGE, Usher, Turner, enlarged vestibular } \\
\text { aqueduct syndrome, Alport syndrome }\end{array}$ \\
\hline Other & $\begin{array}{l}\text { presbyvertigo, vestibular atelectasis, auditory neuropathy } \\
\text { spectrum disorders, etc. }\end{array}$ \\
\hline
\end{tabular}

Overall, additional research is necessary to determine other possible etiologies of BVH and to fully understand the development and clinical course of BVH. The objective of this retrospective study was to further investigate the different etiologies of $\mathrm{BVH}$, the different clinical courses of the disease, and the value of some diagnostic tests currently used in the diagnostic process of $\mathrm{BVH}$. This information could be valuable in the establishment of diagnostic criteria for BVH.

\section{MATERIALS AND METHODS}

\section{Ethical Consideration}

This study was performed in accordance with the guidelines outlined by Dutch legislation. According to the Medical Research Involving Human Subjects Act (WMO) ethical approval was not required due to the retrospective nature and anonymization of these data.

\section{Patients}

A retrospective case review was performed on all patients diagnosed with BVH by, or under the supervision of, the senior author at the vestibular department of Maastricht University Medical Center between 2013 and 2015. It was confirmed that the patients met the following diagnostic inclusion criteria: (1) imbalance and/or oscillopsia during locomotion and (2) reduced responses (summated slow phase mean peak velocity of the nystagmus of less than $20 \% \mathrm{~s}$ ) during bithermal caloric tests. If a patient chart did not comprise all the essential information necessary 
to determine the etiology (including idiopathic etiology), the patient was excluded. Time of diagnosis was based on the date on which the vestibular tests were performed.

\section{Data Collection}

Clinical records were reviewed as well as all qualitative and quantitative data concerning medical history taking, familial history taking (e.g., vestibular disorders, genetic disorders, etc.), vestibular tests (oculomotor tests, caloric tests, torsion swing tests, HITs), neurological examinations, and other diagnostic tests. Other diagnostic tests comprised pure tone and speech audiometry, laboratory tests (vitamin B12, folic acid, HbA1c, TSH, fT4, Borrelial serology, treponemal serology, and genetic tests), cerebral computed tomography, and magnetic resonance imaging. These data were collected in IBM SPSS Statistics 21. The non-vestibular diagnostic tests had only been performed on indication. Indications comprised an idiopathic etiology or an etiology requiring further diagnostic tests (e.g., an MRI of the cerebellopontine angle in Ménière's disease to rule out other possible causes). The etiologies of BVH were classified into three groups: definite, probable, or idiopathic etiology (5).

The caloric tests were performed in all patients with water at 30 and $44^{\circ} \mathrm{C}$. In 151 cases, the volume was $300 \mathrm{ml}$ in $30 \mathrm{~s}$. In three cases, the volume was uncertain, because the caloric test was performed elsewhere. Torsion swing tests were performed using sinusoidal rotation $(0.11 \mathrm{~Hz})$ with a peak velocity of $100 \%$ s. An abnormal response was defined by a gain of $<30 \%$, based on the $95 \%$ confidence interval of the normative data obtained in the vestibular department of Maastricht University Medical Center. The horizontal manual HIT was considered abnormal when overt saccades were observed. The horizontal video head impulse was performed using the Eyeseecam system (EyeSeeCam VOG; EyeSeeCam, Munich, Germany). A video HIT was considered to be abnormal when pathological overt- and/or covert saccades were present in the raw eye traces and/or when patients showed a gain less than 0.6. Missing values from all diagnostic tests were reported as missing data and were not included in the analysis performed. Patients were diagnosed with Ménière's disease using the diagnostic criteria for Ménière's disease (34). The International Headache Society criteria for migraine were used to establish the diagnosis of migraine with or without aura (35).

\section{Statistical Analysis}

Modules from IBM SPSS Statistics 21 were used for statistical analysis. The chi-squared test was applied to test for differences and correlations in nominal values. A significance level of $p<0.05$ was chosen to determine significant differences within and across groups.

\section{RESULTS}

In this study, $154 \mathrm{BVH}$ patients were selected. The mean age of the patients was $60 \pm 12.5$ years (range 19-85) at the time of diagnosis. In one patient, no exact date of assessment could be determined. Of the study population, $52.6 \%$ was male and $47.4 \%$ female. Imbalance was experienced by $98.1 \%$ of the patients and $68.5 \%$ complained of oscillopsia.

\section{Etiology}

Overall, the definite etiology of BVH was determined in $47 \%$ of the cases $(N=72)$ and the probable etiology in $22 \%(N=34)$. In $31 \%$ $(N=48)$, the etiology of BVH remained idiopathic (Figure 1). In this study, BVH resulted from more than 20 different etiologies. The most frequent non-idiopathic etiologies were classified into genetic disorders (17\%), Ménière's disease (16\%), ototoxicity (12\%), infectious diseases (6\%), and neurodegenerative diseases (4\%) (Figure 2). The main groups and main observations will now be discussed.

Regarding genetic disorders, a definite diagnosis with a genetically confirmed mutation in the $\mathrm{COCH}$ gene was most prevalent $(N=15)$. In 11 patients, clinical presentation and family history were highly suggestive for genetic predisposition, but no genetic investigations were performed or no genetic mutation was found. In these patients, a genetic origin was, therefore, classified as the probable etiology.

Thirteen patients were diagnosed with bilateral Ménière's disease and 12 patients with unilateral Ménière's disease. In all 12 patients diagnosed with unilateral Ménière's disease, a bilateral vestibular function loss was found. One patient experienced only one vertigo attack and one patient did not have objective hearing loss according to the diagnostic criteria of Ménière's disease. Therefore, two patients were diagnosed as probable Ménière's disease.

In the group of ototoxicity, BVH was related to treatment with Gentamycin in 14 patients. Two other cases resulted from treatment with Tobramycin and Neomycin and in two patients BVH developed after chemotherapy. In one patient, a probable ototoxic cause was found due to treatment with Quinine.

In the group of infectious diseases, $\mathrm{BVH}$ was definitely related to meningitis in childhood in six patients. Three other cases most likely resulted from Rubella, Epstein-Barr Virus, and Lyme's disease. The group of neurodegenerative diseases consisted solely of six patients with the suspected diagnosis of cerebellar ataxia with neuropathy and bilateral vestibular areflexia syndrome (CANVAS). Strikingly, $23.4 \%$ of all patients $(N=36)$ reported an autoimmune disease in their medical history. Among them, three patients were identified with Cogan's syndrome and only

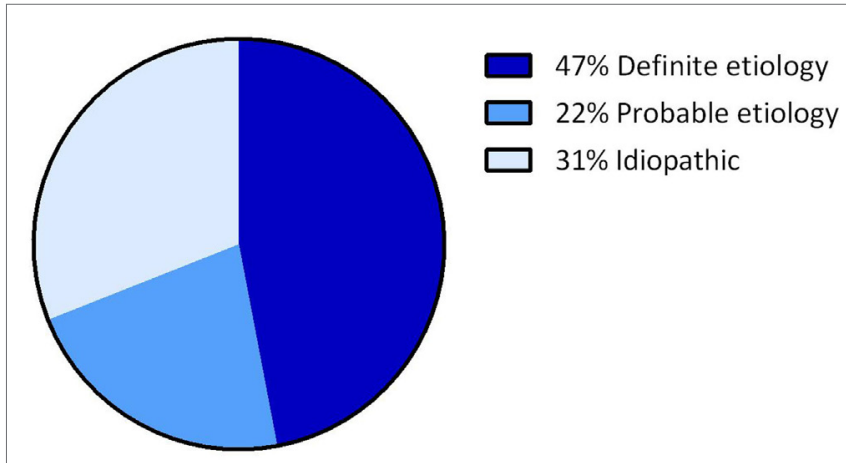

FIGURE 1 | Distribution of certainty of etiology. A definite etiology was found in $47 \%$ of the BVH patients, a probable etiology in $22 \%$ of the $\mathrm{BVH}$ patients and in $31 \%$ the etiology of $\mathrm{BVH}$ remained idiopathic. 


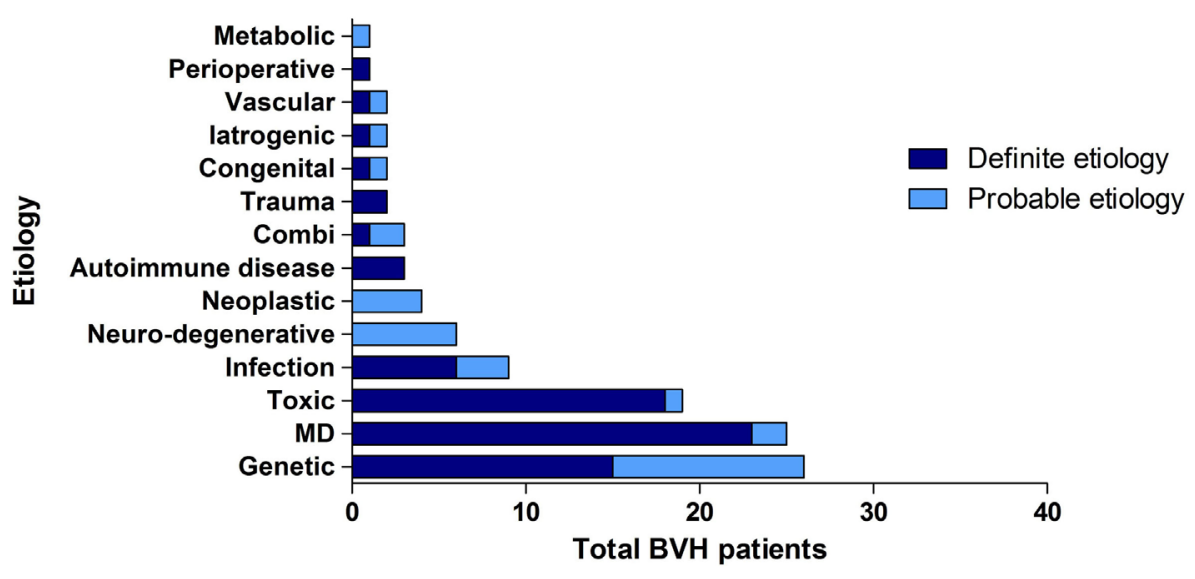

FIGURE 2 | Distribution of etiologies in the BVH group, divided into main groups of etiology and certainty of the etiology.

seven patients suffered from Ménière's disease. In 3\% $(N=5)$, a neoplastic abnormality was found. Four patients suffered from a unilateral vestibular schwannoma and one patient had a skull base meningioma. Head trauma caused BVH in two patients (bilateral skull base fracture and labyrinth contusion) and two patients were known with congenital abnormalities. In two patients, vascular abnormalities (cerebrovascular accident and after carotid endarterectomy) were found. In one patient, BVH developed after organ transplantation and in two patients after bilateral cochlear implantation. In one patient, renal failure was the probable cause of BVH. In three patients, a combination of two different causes resulted in $\mathrm{BVH}$.

In $31 \%(N=48)$, the etiology of BVH remained idiopathic. The gender was equally distributed. Notably, the percentage of migraine among idiopathic patients was significantly higher compared to the group of patients with a definite or probable etiology of BVH ( $p<0.001): 50 \%$ of the idiopathic BVH patients met the International Headache Society criteria (35) for migraine, in contrast to $11 \%$ in the non-idiopathic BVH group (Figure 3 ).

\section{Clinical Subtypes of BVH}

All four previously described clinical subtypes were found in this population (Figure 4). Recurrent episodes of vertigo, followed by the development of BVH were found in $36.4 \%(N=56)$ of all patients. Ménière's disease $(N=23)$, genetic disorders $(N=7)$ and idiopathic BVH $(N=21)$ were most accounted for this clinical subtype. In $36.4 \%$ of the cases $(N=56)$, a rapidly progressive $\mathrm{BVH}$ was found. The main cause of this acute impairment was ototoxicity due to the adverse effect of medication, in particular aminoglycoside antibiotics $(N=14)$.

Thirteen patients with this clinical subtype belonged to the idiopathic group. BVH developed slowly progressively in $20.8 \%$ $(N=32)$ of the patients. In most cases, it comprised patients with a genetic disorder or patients from the idiopathic group. Slowly progressive BVH combined with neurological deficits was found in $4.5 \%(N=7)$ of the cases. Six of these patients were suspected of CANVAS. Missing data arose in $1.9 \%$ of all cases.

\section{Diagnostic Tests}

According to the inclusion criteria, bithermal caloric tests showed reduced responses with a summated slow phase velocity (SPV) of the nystagmus of less than $20 \%$ in all 154 patients. A mean of $6.3 \pm 6.3 \%$ s (range $0-19$ ) was found. The HIT was abnormal in 109 out of 116 tested patients (94\%). The seven head impulses that were considered to be normal, all involved manual HITs. In 38 patients, no data were found concerning the HIT. Data about the torsion swing test were present in 143 patients, of which 94 showed reduced responses (66\%) (Table 2).

Pure tone and speech audiometry was performed in 143 patients. In $49 \%$ of these patients, there was normal hearing or only moderate hearing loss in both ears (modified Fletcher Index: $0-49$ decibel). No hearing loss was found in 22 patients. In $36 \%$ of the patients, an asymmetric hearing loss was found. The results of the pure tone audiometry are presented in Table 3.

When indicated, patients were screened for abnormal levels of vitamin B12, folic acid, HbA1c, TSH, and fT4. Most strikingly, a vitamin B12 deficiency was found in 26 patients and a high folic acid was present in 27 patients. In eight patients, a combination of both findings was seen. Most cases involved a mild vitamin B12 deficiency, probably not related to the development of BVH. High levels of HbA1c were only found in patients already known with diabetes mellitus. In seven patients, abnormal thyroid function was found, of which three patients were known with thyroid dysfunction. In not one of these patients, a relation with regard to the development of BVH was suspected. An overview of blood test results is presented in Table 4. Approximately, one-third of all patients were tested for antinuclear antibodies (ANA) and anti-neutrophil cytoplasmic antibodies (ANCA). In six patients, a positive ANA, without a positive ANCA, was found. One of them was known with autoimmune disorders (rheumatoid arthritis, and diabetes mellitus type I) and one of them with Ménière's disease. In the remaining four patients, the positive ANA was a new finding and they were referred to an immunologist. In only one of them, an underlying autoimmune disorder was suspected and the patient was treated with corticosteroids. In one patient, an atypical pattern 


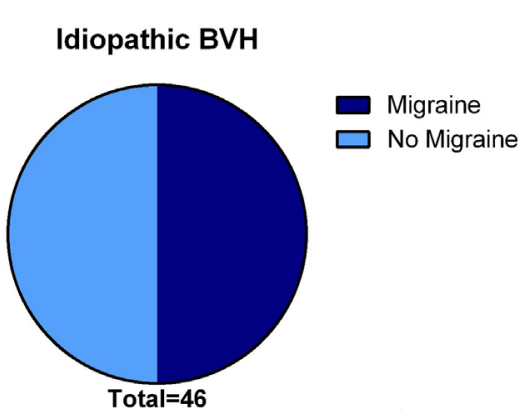

\section{Non-idiopathic BVH}

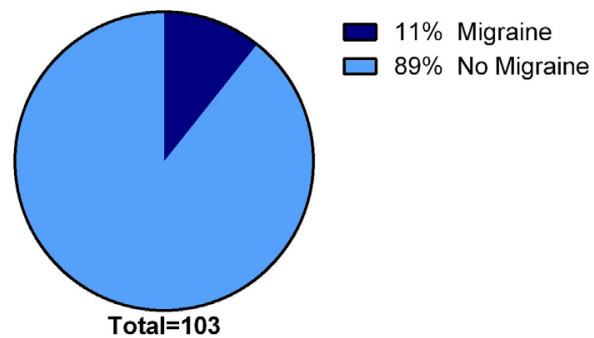

FIGURE 3 | Presence of migraine in the idiopathic BVH group versus the non-idiopathic BVH group. In the idiopathic BVH group, migraine was significantly more present than that in the non-Idiopathic BVH group (50\% versus $11 \%, p<0.001$ ).

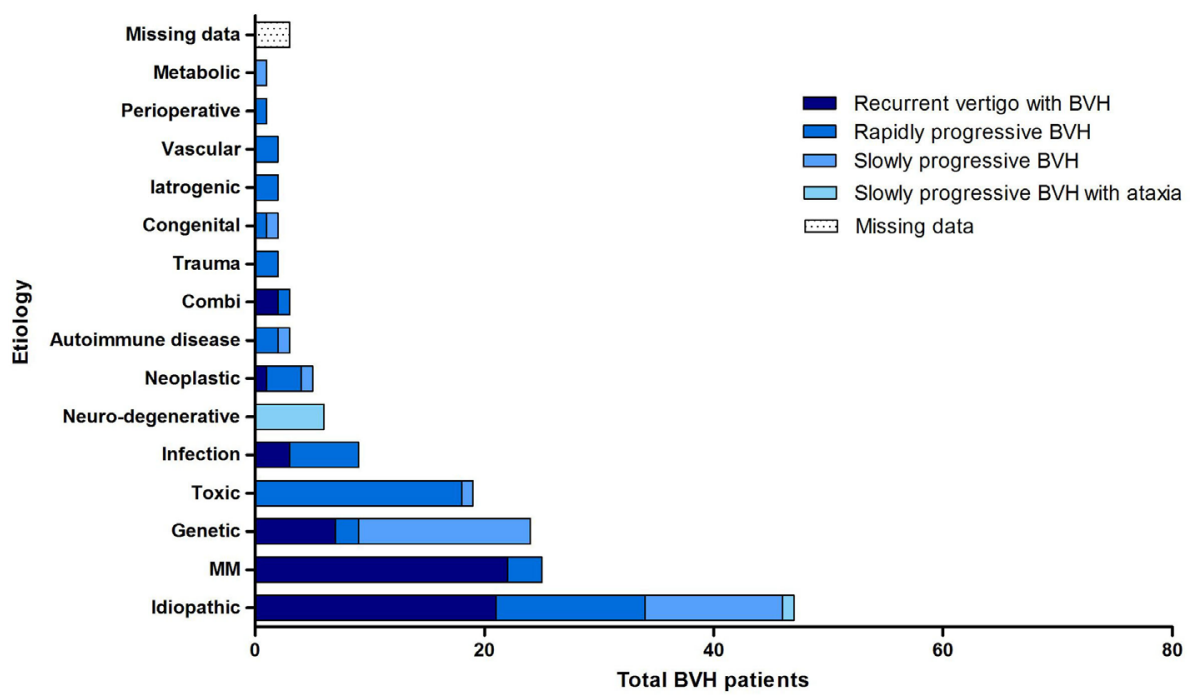

FIGURE 4 | Clinical subtypes of BVH with respect to the etiologies in the BVH group.

TABLE 2 | Results of torsion swing test and head impulse test.

\begin{tabular}{lrcrr}
\hline $\begin{array}{l}\text { Torsion } \\
\text { swing (N) }\end{array}$ & Normal & Abnormal & Not tested & Total \\
\cline { 1 - 1 } (V)HIT & & & & \\
\cline { 1 - 2 } Normal & 4 & 2 & 1 & 7 \\
Abnormal & 36 & 66 & 7 & 109 \\
Missing data & 9 & 26 & 3 & 38 \\
Total & 49 & 94 & 11 & 154 \\
\hline
\end{tabular}

of ANCA was found, without a positive ANA. This patient was already known with an autoimmune disorder (rheumatoid arthritis) (Table 5). Seventy-three patients were tested for antibodies against the Borrelia bacteria, of which five showed results of a previous Borrelial infection, without any signs of a recent infection or a history of typical complaints of neuroborreliosis. If necessary, a virologist was consulted. In two cases (3\%), it was decided to still treat the patients against the Borrelial infection. Forty-one patients were screened for antibodies against the Treponema pallidum bacteria and no abnormalities were found (Table 5).

Cerebral imaging studies were performed in 127 patients $(N=119 \mathrm{MRI} ; N=8 \mathrm{CT}$ ) (Table 6). The following abnormalities were found: cerebellar atrophy $(N=4)$, cerebellar lesions $(N=3)$, unilateral vestibular schwannoma $(N=4$, of which two patients did not have asymmetric hearing loss), supra- or infratentorial vascular lesions $(N=5)$, a skull base meningioma $(N=1)$, and abnormalities of the semicircular canals (e.g., fibrosis, calcification, inflammation, $N=4$ ). No new abnormalities were found with computerized tomography. In three patients, abnormalities found with cerebral imaging were already expected due to previous findings on MRI or medical history. In 18 patients (14\%), cranial imaging studies revealed new findings.

\section{DISCUSSION}

In this study, 154 patients were evaluated with regard to the different etiologies of $\mathrm{BVH}$, clinical subtypes of $\mathrm{BVH}$, and diagnostic 
TABLE 3 | Results of pure tone audiometry.

\begin{tabular}{|c|c|c|c|c|c|}
\hline \multirow[t]{2}{*}{ Impairment hearing loss } & \multirow[t]{2}{*}{ FI-high (dB) } & \multicolumn{2}{|c|}{ Asymmetric hearing } & \multicolumn{2}{|c|}{ Symmetric hearing } \\
\hline & & Best ear & Worst ear & Best ear & Worst ear \\
\hline No impairment & $0-19$ & 17 & 0 & 28 & 21 \\
\hline Slight impairment & 20-34 & 10 & 6 & 19 & 21 \\
\hline Moderate impairment & $35-49$ & 10 & 8 & 11 & 14 \\
\hline Significant impairment & $50-64$ & 10 & 3 & 9 & 3 \\
\hline Severe impairment & $65-79$ & 3 & 8 & 7 & 11 \\
\hline Profound impairment: including deafness & $>80$ & 5 & 30 & 14 & 18 \\
\hline Not tested & 11 & & & & \\
\hline Total patients & 154 & 55 & 55 & 88 & 88 \\
\hline
\end{tabular}

TABLE 4 | Blood test results in BVH patients.

\begin{tabular}{|c|c|c|c|c|c|}
\hline Results & Vitamin B12 & Folic acid & HbA1c & TSH & fT4 \\
\hline Low & $26^{a}$ & 1 & - & 2 & - \\
\hline Normal & 39 & 32 & 44 & 60 & 56 \\
\hline High & - & 27 & 4 & 3 & 2 \\
\hline Total & 65 & 60 & 48 & 65 & 58 \\
\hline Not tested & 89 & 94 & 106 & 89 & 96 \\
\hline
\end{tabular}

aThree patients were known with anemia in medical history due to Vitamin B12 deficiency.

TABLE 5 | Results auto-antibodies and bacteria in BVH patients.

\begin{tabular}{|c|c|c|c|c|c|}
\hline Results & ANA & ANCA & Treponema pallidum (IgM) & Borrelia bacteria (IgM) & Borrelia bacteria (IgG) \\
\hline Negative & 50 & 51 & 41 & 71 & 66 \\
\hline Positive & 6 & 0 & 0 & 2 & 7 \\
\hline Atypical & 0 & 1 & - & - & - \\
\hline Total & 56 & 53 & 41 & 73 & 73 \\
\hline Clinical implication & 1 & 0 & 0 & 0 & 2 \\
\hline Not tested & 98 & 102 & 113 & 81 & 81 \\
\hline
\end{tabular}

TABLE 6 | MRI and CT in BVH patients.

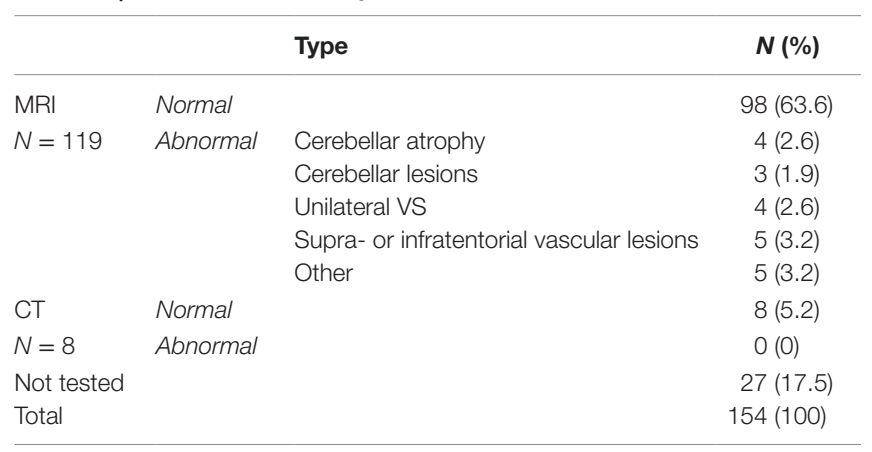

tests to establish the diagnosis of BVH. Although the etiology of BVH could often be defined, $31 \%$ of the cases remained idiopathic. Remarkably, the prevalence of migraine in this idiopathic group was significantly higher compared to the non-idiopathic group. The different etiologies of BVH were partly reflected by the four clinical subtypes, as previously described $(4,31)$. Not all patients showed a pathological HIT or reduced responses with the torsion swing tests. Audiometry often contributed to the determination of the etiology (e.g., Ménière's disease) and in this population, blood tests did not often contribute to the determination of the cause of BVH. Abnormal cerebral imaging was found in 21 patients.

\section{Etiologies}

Patients were classified as having a definite, probable, or idiopathic etiology of BVH. Once etiology was not entirely certain or could not be confirmed with genetic research (e.g., CANVAS patients), etiology was described as a probable cause of BVH. Therefore, the amount of definite causes of $\mathrm{BVH}$ is probably a conservative estimation.

Genetic disorders and Ménière's disease were the most frequent non-idiopathic causes of $\mathrm{BVH}$ in this population. Regarding genetic disorders, most patients presented with a mutation in their $\mathrm{COCH}$ gene. This mutation has been identified to cause autosomal dominant non-syndromic hearing loss accompanied by vestibular disorders (DNFA9) (13). Due to the high prevalence of DNFA9 in the Netherlands and Flanders (36), it is possible that the presence of DFNA9 was higher in this population of BVH patients. Although a strong underlying familial character seems to be present in multiple vestibular disorders, genome-wide association studies remain very difficult to perform, partly due to the clinical heterogeneity of vestibular disorders $(12,37)$. Therefore, $\mathrm{BVH}$ patients suspected of a genetic disorder (based on clinical 
manifestation and family history) other than a confirmed $\mathrm{COCH}$ gene mutation, were classified as having a genetic disorder as the probable cause of BVH.

Regarding Ménière's disease, a unilateral Ménière's disease was found in 12 cases, in which no definite etiology could be determined to explain the vestibular hypofunction of the "unaffected" side. In some cases, bilateral Ménière's disease was suspected on history, but no objective hearing loss could be defined with pure tone audiometry. However, other cases did not report any cochlear symptoms on the "unaffected" side. It probably shows that the vestibular system can (already) be affected bilaterally, while cochlear symptoms are present on only one side. This is in line with a previous study that showed that abnormal VEMP's were present in $27 \%$ of the "unaffected" ears in unilateral Ménière's disease (38). This bilateral vestibular involvement in a clinically unilateral Ménière's disease has also important clinical implications: it shows that the use of diagnostic parameters, such as the interaural asymmetry in calorics and VEMP's is not sufficient for diagnostic purposes in Ménière's disease (3, 31, 38, 39).

Furthermore, when intratympanic gentamicin treatment is considered for intractable unilateral Ménière's disease (40), an ENG should always be performed to determine the vestibular function of the "unaffected" side. If not performed, this could imply a risk of inducing an even more severe BVH.

Neurodegenerative diseases and ataxia were found in only seven patients, which varies tremendously compared to earlier studies $(5,11)$. This finding could imply that the distribution of the etiologies of BVH depends on the clinical setting in which patients are seen. In this study, patients were selected at the vestibular department of the Department of Otorhinolaryngology and Head and Neck Surgery in Maastricht University Medical Centre, whereas in previous studies patients were selected in neurological departments $(5,11)$. This could explain the low percentage of $\mathrm{BVH}$ with neurological deficits and might also be the reason why fewer patients showed a slow progression of $\mathrm{BVH}$, which is usually seen in patients with neurological disorders (20). Overall, the "real" BVH population is probably a reflection of both study populations.

A unilateral vestibular schwannoma with bilateral vestibular loss was found in four patients. This is an atypical finding, since $\mathrm{BVH}$ is mainly found when schwannomas appear bilaterally as in neurofibromatosis type II (41), not unilaterally. To our knowledge, literature has not reported about this type of finding. However, most studies about schwannomas report on labyrinthine asymmetry in calorics, without incorporating the absolute values (42-46). This increases the chance of missing a symmetric low vestibular response (3). A possible explanation for the vestibular loss on the contralateral side could be an endolymphatic hydrops on this side (47). Nevertheless, regarding the etiology of vestibular hypofunction on the side without a schwannoma, a definite cause could not be established, although in one out of the four cases, vestibular symptoms worsened after treatment with Gamma Knife.

Among all 154 BVH patients, 23.4\% were known with autoimmune disorders in their medical history. Only in the three patients with Cogan's syndrome, a definite causal relationship could be identified between BVH and autoimmunity. Seven of the patients with a known autoimmune disorder suffered from Ménière's disease, resulting in a possible link between $\mathrm{BVH}$ and autoimmunity $(48,49)$. However, the percentage of autoimmune disorders in western countries is only around $8 \%$ of the total population (50), in contrary to the $23.4 \%$ found in this population. Therefore, autoimmune disorders might not always cause $\mathrm{BVH}$ directly, but could probably play a modulating role in the development of the disease.

In $31 \%$, the etiology of BVH remained idiopathic. This differs from previous results in a large relatively recent study, in which in approximately $51 \%$ no definite or probable etiology of BVH could be defined (5). This difference could partially be explained by the increased knowledge regarding the underlying cause of $\mathrm{BVH}$, the relatively high prevalence of genetic disorders in this population and the different clinical settings in which patients were seen. Notably, $50 \%$ of the idiopathic patients reported a history of migraine headaches according to the criteria of the International Headache Society. This was significantly higher than that in the non-idiopathic group and higher than would be expected in the normal population: migraine normally affects only $8 \%$ of males and $17 \%$ of females $(51,52)$. Next to the link between migraine and vertigo in vestibular migraine $(30,35)$, a suggestive linkage between migraine and BVH has been proposed before $(4,53)$. This study seems to confirm that migraine might play a significant role in the idiopathic variant of BVH and it shows the importance of screening for migraine features in the diagnostic process of $\mathrm{BVH}$. In the future, additional studies could focus on the role of migraine in BVH and, in particular, the non-classical manifestations of this disease.

\section{Clinical Subtypes}

Most non-idiopathic BVH patients presented with a clinical subtype that would be expected with respect to their etiology (e.g., mainly rapidly progressive symptoms after ototoxic medication). Among the idiopathic BVH patients, all four different clinical subtypes were reported, showing an overlap between the clinical presentations of non-idiopathic and idiopathic BVH. This is one of the contributing factors of the challenging diagnostic process of $\operatorname{BVH}(3,4,31)$.

\section{Vestibular Tests and Inclusion Criteria Caloric Test}

Inclusion criteria comprised reduced responses during bithermal caloric irrigations. However, absent responses during bithermal caloric irrigations do not necessarily indicate a complete loss of the vestibular function (7). Therefore, symptoms had to match caloric findings in order to get a more specific selection of patients. In addition to that, other vestibular tests were evaluated.

\section{(Video) Head Impulse Test}

In contrast to previously proposed criteria (7), a positive HIT was not included in the inclusion criteria due to the following reasons: (1) a bilateral pathological HIT was previously found in only $73 \%$ of a BVH population, suggesting that a normal HIT does not necessarily rule out a vestibular deficiency (1). (2) A manual HIT observed with the naked eye of experts is false negative in 
about $50 \%$ of the patients, when compared to the VHIT (31). In this study, all HITs performed with a VHIT-system showed pathological responses, in contrary to some manually performed HITs. Since a manual HIT can be false negative, it cannot be ruled out that (some of) the manual HITs in this study were actually false negative ones. Nevertheless, around 94\% of all HITs corresponded with the findings during bithermal caloric irrigations. Taking these findings into account for the future diagnostic process of BVH, we would strongly suggest performing a VHIT instead of a manual HIT.

\section{Torsion Swing Test}

Although the torsion swing test is sometimes considered to be the "gold standard" for BVH (3), it was not included in the inclusion criteria since it is very specific, but seems to have a lower sensitivity, leading to false negative results $(7,31)$. In this study, only $66 \%$ of the tested patients showed an abnormal response with the torsion swing test at $0.11 \mathrm{~Hz}$, implying a possible lack of sensitivity. The preservation of vestibular responses in the torsion swing test can possibly be explained by two hypotheses. (1) The torsion swing test stimulates the vestibular system closer to the optimum frequency sensitivity of the semicircular canals than the caloric test and the HIT $(54,55)$. When vestibular function would decline evenly distributed between frequencies in $\mathrm{BVH}$, the vestibular system is most likely to longer preserve its response around the frequencies with optimum sensitivity. (2) In contrast to the caloric test and HIT, torsion swing testing is most likely to have more input from the otolith system (7). Since VEMP's and DVAs were performed in only the minority of patients, they were not used in the total analysis. Therefore, inputs from otoliths during the torsion swing test could not be ruled out in this $\mathrm{BVH}$ population. For the future diagnostic process of $\mathrm{BVH}$, torsion swing testing can be used complementarily (e.g., measure severity of BVH when the caloric test and HIT show no responses anymore) but not as the only test to diagnose BVH $(31,56)$.

\section{Limitations of This Study Regarding Vestibular Tests}

Inclusion criteria comprised vestibular symptoms combined with reduced responses during bithermal caloric tests. The selected patient group does, therefore, probably not reflect the whole $\mathrm{BVH}$ population, since the caloric test can miss, e.g., selective mid- to high-frequency loss of canals or isolated dysfunction of the otoliths. Depending on the diagnostic criteria for BVH, this leads to a lower sensitivity $(7,57)$. Next to this, specificity could be compromised by the fact that reduced caloric responses not always indicate a true vestibular loss. Uncontrollable factors, such as anatomy of the temporal bone could lead to reduced temperature conduction and as a consequence lead to false-positive results (58). However, since no diagnostic criteria for BVH are available yet and VEMP's and DVAs were only performed in the minority of patients, it was decided to only use the caloric test as a parameter for the vestibular function. Nevertheless, VEMP's, DVAs, and motion perception might play a more important role in the future diagnostic process of BVH $(7,31,59-62)$ and our research group is, therefore, prospectively testing these parameters in BVH patients (not yet published).

\section{Other Diagnostic Tests}

Currently, many other diagnostic tests are used for determination of coexisting problems or the etiology of BVH (31). Some of them will be briefly discussed below.

\section{Audiometry}

Audiometry often contributed to the determination of the underlying etiology (e.g., Ménière's disease) of BVH and seems to be a valuable diagnostic tool when indicated. Considering otoacoustic emissions were not performed in these BVH patients, auditory neuropathy could have been missed during the determination of the etiology. Nevertheless, speech audiometry was performed on these patients, and as poor speech recognition is also a criterion of auditory neuropathy disorder, this obstacle could partially be overcome by these tests $(32,63-65)$. Notably, in approximately half of the patients, no to moderate hearing loss was found by using pure tone and speech audiometry. It shows the importance of hearing preservation during vestibular implantation, in case a vestibular prosthesis would become a clinically useful therapeutic device in the future (66-71).

\section{Blood Tests}

In this study, blood tests results of vitamin B12, folic acid, HbA1c, $\mathrm{TSH}$, and fT4 showed that in case of abnormal blood results, no strong clinical implications were found with regard to the diagnosis or treatment of BVH. Limitation of this retrospective study was the fact that patients were referred to their general practitioner or other specialists for further diagnostics and follow-up of their vitamin B12 deficiency and high levels of folic acid. Not all data could be obtained. Nevertheless, the use of some of the blood tests (HbA1c, $\mathrm{TSH}, \mathrm{fT} 4$ ) could be reconsidered in the diagnostic trial of BVH.

Although autoimmunity might play a role in the pathogenesis of some BVH subpopulations (72), the use of routine ANA and ANCA antibodies yielded little in this population. Seven patients showed positive results for ANA or ANCA, but some of the ANA positive results might be attributed to the fact that ANA positivity is also found in a certain percentage of normal individuals (73). The positive ANA in the patient with Ménière's disease could be explained by a relation between Ménière's disease and autoimmune diseases, described in earlier studies $(48,49,74)$. Eventually, only 1 out of 157 tests had a clinical consequence: the patient was treated for a suspected autoimmune disorder. Therefore, in the future diagnostic process of $\mathrm{BVH}$, routine testing of ANA and ANCA could probably be redundant and might be reserved for more specific cases with a higher suspicion of an underlying autoimmune disorder. However, the routine use of inner ear-specific auto-antibodies should still be investigated (72).

Two out of 73 patients tested for Borrelia were eventually treated for a Borrelial infection. The relation between BVH and Borrelia remained questionable in these cases due to the absence of typical complaints of neuroborreliosis and the fact that it can be a diagnostic challenge to prove that a neurological manifestation has been caused by Borrelia (75). This is due to the low positive predictive value of the test. Still, the negative predictive value is very high $(76,77)$. Although only a few cases were suspected of BVH due to a Borrelial infection, it should be noted that Borrelia 
is a non-endemic infectious disease in the demographic area in which patients were selected for this study (78). Therefore, blood tests to identify infection with the Borrelia bacteria might still be important, especially in areas were the bacteria is active.

Neurosyphilis has also a low incidence in the Netherlands, partially explaining the absence of antibodies against the Treponema pallidum bacteria in this BVH population. Nevertheless, screening for Treponema can still be considered in risk groups and in areas where treponemes are known to be endemic $(79,80)$.

\section{Cerebral Imaging}

Cerebral imaging studies revealed new findings in 18 patients, which is less compared to previous studies $(5,81)$, but this is again probably related to the study group. Cerebral imaging has shown to play an important role in the diagnosis of $\mathrm{BVH}$, reflected by the new findings detected by MRI. In addition to that, cerebral imaging is also inherent to some diagnostic work-ups (e.g., an MRI in Ménière's disease to rule out other possible causes) (34). Therefore, in the future diagnostic process of BVH, cerebral imaging should be performed in cases with a less clear etiology of BVH as well as within the framework of diagnostic work-ups. In most cases, MRI would be the preferred modality.

\section{REFERENCES}

1. Agrawal Y, Bremova T, Kremmyda O, Strupp M. Semicircular canal, saccular and utricular function in patients with bilateral vestibulopathy: analysis based on etiology. J Neurol (2013) 260(3):876-83. doi:10.1007/ s00415-012-6724-y

2. Zingler VC, Weintz E, Jahn K, Bötzel K, Wagner J, Huppert D, et al. Saccular function less affected than canal function in bilateral vestibulopathy. J Neurol (2008) 255(9):1332-6. doi:10.1007/s00415-008-0887-6

3. Hain TC, Cherchi M, Yacovino DA. Bilateral vestibular loss. Semin Neurol (2013) 33(3):195-203. doi:10.1055/s-0033-1354597

4. Jen JC. Bilateral vestibulopathy: clinical, diagnostic, and genetic considerations. Semin Neurol (2009) 29(5):528-33. doi:10.1055/s-0029-1241035

5. Zingler VC, Weintz E, Jahn K, Huppert D, Cnyrim C, Brandt T, et al. Causative factors, epidemiology, and follow-up of bilateral vestibulopathy. Ann N Y Acad Sci (2009) 1164:505-8. doi:10.1111/j.1749-6632.2009.03765.x

6. van de Berg R, Guinand N, Nguyen TAK, Ranieri M, Cavuscens S, Guyot J-P, et al. The vestibular implant: frequency-dependency of the electrically evoked vestibulo-ocular reflex in humans. Front Syst Neurosci (2015) 8:255. doi:10.3389/fnsys.2014.00255

7. Kim S, Oh YM, Koo JW, Kim JS. Bilateral vestibulopathy: clinical characteristics and diagnostic criteria. Otol Neurotol (2011) 32(5):812-7. doi:10.1097/ MAO.0b013e31821a3b7d

8. Ward BK, Agrawal Y, Hoffman HJ, Carey JP, Della Santina CC. Prevalence and impact of bilateral vestibular hypofunction: results from the 2008 US National Health Interview Survey. JAMA Otolaryngol Head Neck Surg (2013) 139(8):803-10. doi:10.1001/jamaoto.2013.3913

9. Guinand N, Boselie F, Guyot JP, Kingma H. Quality of life of patients with bilateral vestibulopathy. Ann Otol Rhinol Laryngol (2012) 121(7):471-7. doi:10.1177/000348941212100708

10. Grill E, Strupp M, Müller M, Jahn K. Health services utilization of patients with vertigo in primary care: a retrospective cohort study. J Neurol (2014) 261(8):1492-8. doi:10.1007/s00415-014-7367-y

11. Rinne T, Bronstein AM, Rudge P, Gresty MA, Luxon LM. Bilateral loss of vestibular function: clinical findings in 53 patients. J Neurol (1998) 245(6-7):314-21. doi:10.1007/s004150050225

12. Requena T, Espinosa-Sanchez JM, Lopez-Escamez JA. Genetics of dizziness: cerebellar and vestibular disorders. Curr Opin Neurol (2014) 27(1):98-104. doi:10.1097/WCO.0000000000000053

\section{CONCLUSION}

Bilateral vestibular hypofunction is a heterogeneous condition with various etiologies and clinical characteristics. Migraine seems to play a significant role in idiopathic BVH and autoimmunity could be a modulating factor in the development of BVH. The distribution of etiologies of BVH probably depends on the clinical setting. In the diagnostic process of $\mathrm{BVH}$, the routine use of some blood tests can be reconsidered and a low-threshold use of audiometry and cerebral imaging is advised. The torsion swing test is not the "gold standard" for diagnosing BVH due to its lack of sensitivity. Future diagnostic criteria of BVH should consist of standardized vestibular tests combined with a history that is congruent with the vestibular findings.

\section{AUTHOR CONTRIBUTIONS}

All authors contributed extensively to the work presented in this paper. FL and PV wrote the manuscript. RB supervised the writing and edited the manuscript. HK supervised the writing, reviewed the manuscript, and edited the manuscript. NG and RS reviewed the manuscript and edited the manuscript.

13. Tsukada K, Ichinose A, Miyagawa M, Mori K, Hattori M, Nishio SY, et al. Detailed hearing and vestibular profiles in the patients with $\mathrm{COCH}$ mutations. Ann Otol Rhinol Laryngol(2015) 124(Suppl 1):100S-10S. doi:10.1177/0003489415573074

14. Ghavami Y, Mahboubi H, Yau AY, Maducdoc M, Djalilian HR. Migraine features in patients with Meniere's disease. Laryngoscope (2016) 126(1):163-8. doi:10.1002/lary.25344

15. Radtke A, Lempert T, Gresty MA, Brookes GB, Bronstein AM, Neuhauser H. Migraine and Meniere's disease: is there a link? Neurology (2002) 59(11):1700-4. doi:10.1212/01.WNL.0000036903.22461.39

16. Clemmens C, Ruckenstein M. Characteristics of patients with unilateral and bilateral Meniere's disease. Otol Neurotol (2012) 33(7):1266-9. doi:10.1097/ MAO.0b013e31826426b9

17. Ishiyama G, Ishiyama A, Kerber K, Baloh RW. Gentamicin ototoxicity: clinical features and the effect on the human vestibulo-ocular reflex. Acta Otolaryngol (2006) 126(10):1057-61. doi:10.1080/00016480600606673

18. Cushing SL, Papsin BC, Rutka JA, James AL, Blaser SL, Gordon KA. Vestibular end-organ and balance deficits after meningitis and cochlear implantation in children correlate poorly with functional outcome. Otol Neurotol (2009) 30(4):488-95. doi:10.1097/MAO.0b013e31819bd7c8

19. Farshad-Amacker NA, Scheffel H, Frauenfelder T, Alkadhi H. Brainstem abnormalities and vestibular nerve enhancement in acute neuroborreliosis. BMC Res Notes (2013) 6:551. doi:10.1186/1756-0500-6-551

20. Szmulewicz DJ, McLean CA, MacDougall HG, Roberts L, Storey E, Halmagyi GM. CANVAS an update: clinical presentation, investigation and management. J Vestib Res (2014) 24(5-6):465-74. doi:10.3233/VES-140536

21. Szmulewicz DJ, Waterston JA, MacDougall HG, Mossman S, Chancellor AM, McLean CA, et al. Cerebellar ataxia, neuropathy, vestibular areflexia syndrome (CANVAS): a review of the clinical features and video-oculographic diagnosis. Ann N Y Acad Sci (2011) 1233:139-47. doi:10.1111/j.1749-6632.2011.06158.x

22. Bovo R, Ciorba A, Martini A. Vertigo and autoimmunity. Eur Arch Otorhinolaryngol (2010) 267(1):13-9. doi:10.1007/s00405-009-1122-5

23. Buniel MC, Geelan-Hansen K, Weber PC, Tuohy VK. Immunosuppressive therapy for autoimmune inner ear disease. Immunotherapy (2009) 1(3): 425-34. doi:10.2217/imt.09.12

24. Greco A, Gallo A, Fusconi M, Magliulo G, Turchetta R, Marinelli C, et al. Cogan's syndrome: an autoimmune inner ear disease. Autoimmun Rev (2013) 12(3):396-400. doi:10.1016/j.autrev.2012.07.012

25. Berkowitz O, Iyer AK, Kano H, Talbott EO, Lunsford LD. Epidemiology and environmental risk factors associated with vestibular schwannoma. World Neurosurg (2015) 84(6):1674-80. doi:10.1016/j.wneu.2015.07.007 
26. Brusis T. [Sensorineural hearing loss after dull head injury or concussion trauma]. Laryngorhinootologie (2011) 90(2):73-80. doi:10.105 5/s-0030-1267938

27. Huygen PL, Hinderink JB, van den Broek P, van den Borne S, Brokx JP, Mens LH, et al. The risk of vestibular function loss after intracochlear implantation. Acta Otolaryngol Suppl (1995) 520(Pt 2):270-2. doi:10.3109/00016489509125245

28. Lempert T, Neuhauser $H$. Epidemiology of vertigo, migraine and vestibular migraine. J Neurol (2009) 256(3):333-8. doi:10.1007/s00415-009-0149-2

29. Cha YH, Baloh RW. Migraine associated vertigo. JClin Neurol (2007) 3(3):121-6. doi:10.3988/jcn.2007.3.3.121

30. Radtke A, Neuhauser H, von Brevern M, Hottenrott T, Lempert T. Vestibular migraine - validity of clinical diagnostic criteria. Cephalalgia (2011) 31(8):906-13. doi:10.1177/0333102411405228

31. van de Berg R, van Tilburg M, Kingma H. Bilateral vestibular hypofunction: challenges in establishing the diagnosis in adults. ORL J Otorhinolaryngol Relat Spec (2015) 77(4):197-218. doi:10.1159/000433549

32. Nash R, Veness J, Wyatt M, Raglan E, Rajput K. Vestibular function in children with auditory neuropathy spectrum disorder. Int J Pediatr Otorhinolaryngol (2014) 78(8):1269-73. doi:10.1016/j.ijporl.2014.05.008

33. Weegerink NJ, Schraders M, Leijendeckers J, Slieker K, Huygen PL, Hoefsloot L, et al. Audiometric characteristics of a Dutch family with Muckle-Wells syndrome. Hear Res (2011) 282(1-2):243-51. doi:10.1016/j.heares.2011.07.006

34. Lopez-Escamez JA, Carey J, Chung WH, Goebel JA, Magnusson M, Mandalà M, et al. Diagnostic criteria for Meniere's disease. J Vestib Res (2015) 25(1):1-7. doi:10.3233/VES-150549

35. Headache Classification Committee of the International Headache S. The international classification of headache disorders, 3rd edition (beta version). Cephalalgia (2013) 33(9):629-808. doi:10.1177/0333102413485658

36. Cremers CWRJ, Kemperman MH, Bom SJH, Huygen PLM, Verhagen WIM, Kremer JMJ. Van gen naar ziekte; een op middelbare leeftijd optredende progressieve cochleavestibulaire disfunctie (DFNA9). Ned Tijdschr Geneeskd (2005) 149(47):2619-21.

37. Alford RL, Arnos KS, Fox M, Lin JW, Palmer CG, Pandya A, et al. American College of Medical Genetics and Genomics guideline for the clinical evaluation and etiologic diagnosis of hearing loss. Genet Med (2014) 16(4):347-55. doi:10.1038/gim.2014.2

38. Lin MY, Timmer FC, Oriel BS, Zhou G, Guinan JJ, Kujawa SG, et al. Vestibular evoked myogenic potentials (VEMP) can detect asymptomatic saccular hydrops. Laryngoscope (2006) 116(6):987-92. doi:10.1097/01. mlg.0000216815.75512.03

39. Taylor RL, Wijewardene AA, Gibson WP, Black DA, Halmagyi GM, Welgampola MS. The vestibular evoked-potential profile of Meniere's disease. Clin Neurophysiol (2011) 122(6):1256-63. doi:10.1016/j.clinph.2010.11.009

40. De Beer L, Stokroos R, Kingma H. Intratympanic gentamicin therapy for intractable Meniere's disease. Acta Otolaryngol (2007) 127(6):605-12. doi:10.1080/00016480600951475

41. Black FO, Brackmann DE, Hitselberger WE, Purdy J. Preservation of auditory and vestibular function after surgical removal of bilateral vestibular schwannomas in a patient with neurofibromatosis type 2. Am J Otol (1995) 16(4):431-43.

42. Suzuki M, Yamada C, Inoue R, Kashio A, Saito Y, Nakanishi W. Analysis of vestibular testing in patients with vestibular schwannoma based on the nerve of origin, the localization, and the size of the tumor. Otol Neurotol (2008) 29(7):1029-33. doi:10.1097/MAO.0b013e3181845854

43. Gouveris H, Helling K, Victor A, Mann W. Comparison of electronystagmography results with dynamic posturography findings in patients with vestibular schwannoma. Acta Otolaryngol (2007) 127(8):839-42. doi:10.1080/00016480601075357

44. Day AS, Wang CT, Chen CN, Young YH. Correlating the cochleovestibular deficits with tumor size of acoustic neuroma. Acta Otolaryngol (2008) 128(7):756-60. doi:10.1080/00016480701749240

45. Stipkovits EM, Van Dijk JE, Graamans K. Electronystagmographic changes in patients with unilateral vestibular schwannomas in relation to tumor progression and central compensation. Eur Arch Otorhinolaryngol (1999) 256(4):173-6. doi:10.1007/s004050050135

46. Hu YF, Cheng PW, Young YH. Comparison of vestibular function between large cerebellopontine angle meningioma and schwannoma. Acta Otolaryngol (2009) 129(2):161-5. doi:10.1080/00016480802126553
47. Röösli C, Chhan D, Halpin C, Rosowski JJ. Comparison of umbo velocity in air- and bone-conduction. Hear Res (2012) 290(1-2):83-90. doi:10.1016/j. heares.2012.04.011

48. Gazquez I, Soto-Varela A, Aran I, Santos S, Batuecas A, Trinidad G, et al. High prevalence of systemic autoimmune diseases in patients with Meniere's disease. PLoS One (2011) 6(10):e26759. doi:10.1371/journal.pone.0026759

49. Ruckenstein MJ, Prasthoffer A, Bigelow DC, Von Feldt JM, Kolasinski SL. Immunologic and serologic testing in patients with Meniere's disease. Otol Neurotol (2002) 23(4):discussion520-1. doi:10.1097/00129492-200207000-00021

50. Sitsen A. Auto-Immuunziekten. Houten: AccreDidact (2014).

51. Gazquez I, Lopez-Escamez JA. Genetics of recurrent vertigo and vestibular disorders.Curr Genomics (2011) 12(6):443-50.doi:10.2174/138920211797248600

52. Stovner LJ, Zwart JA, Hagen K, Terwindt GM, Pascual J. Epidemiology of headache in Europe. Eur JNeurol (2006) 13(4):333-45. doi:10.1111/j.1468-1331.2006.01184.x

53. Jen JC, Wang H, Lee H, Sabatti C, Trent R, Hannigan I, et al. Suggestive linkage to chromosome $6 \mathrm{q}$ in families with bilateral vestibulopathy. Neurology (2004) 63(12):2376-9. doi:10.1212/01.WNL.0000149498.79541.49

54. Baloh RW, Sills AW, Honrubia V. Impulsive and sinusoidal rotatory testing: a comparison with results of caloric testing. Laryngoscope (1979) 89(4):646-54. doi:10.1288/00005537-197904000-00013

55. McGarvie LA, Curthoys IS, MacDougall HG, Halmagyi GM. What does the head impulse test versus caloric dissociation reveal about vestibular dysfunction in Meniere's disease? Ann N Y Acad Sci (2015) 1343:58-62. doi:10.1111/ nyas. 12687

56. Clark KF. Torsion swing chair. Ear Hear (1986) 7(3):191-7. doi:10.1097/00003446-198606000-00012

57. Fujimoto C, Murofushi T, Sugasawa K, Chihara Y, Ushio M, Yamasoba T, et al. Bilateral vestibulopathy with dissociated deficits in the superior and inferior vestibular systems. Ann Otol Rhinol Laryngol (2012) 121(6):383-8. doi:10.1177/000348941212100604

58. Van Der Stappen A, Wuyts FL, Van De Heyning PH. Computerized electronystagmography: normative data revisited. Acta Otolaryngol (2000) 120(6):724-30. doi:10.1080/000164800750000243

59. Guinand N, Pijnenburg M, Janssen M, Kingma H. Visual acuity while walking and oscillopsia severity in healthy subjects and patients with unilateral and bilateral vestibular function loss. Arch Otolaryngol Head Neck Surg (2012) 138(3):301-6. doi:10.1001/archoto.2012.4

60. Priesol AJ, Valko Y, Merfeld DM, Lewis RF. Motion perception in patients with idiopathic bilateral vestibular hypofunction. Otolaryngol Head Neck Surg (2014) 150(6):1040-2. doi:10.1177/0194599814526557

61. Mardirossian V, Karmali F, Merfeld D. Thresholds for human perception of roll tilt motion: patterns of variability based on visual, vestibular, and mixed cues. Otol Neurotol (2014) 35(5):857-60. doi:10.1097/ MAO.0000000000000346

62. Lewis RF, Priesol AJ, Nicoucar K, Lim K, Merfeld DM. Abnormal motion perception in vestibular migraine. Laryngoscope (2011) 121(5):1124-5. doi:10.1002/lary.21723

63. Sinha SK, Shankar K, Sharanya R. Cervical and ocular vestibular evoked myogenic potentials test results in individuals with auditory neuropathy spectrum disorders. Audiol Res (2013) 3(1):e4. doi:10.4081/audiores.2013.e4

64. Starr A, Rance G. Auditory neuropathy. Handb Clin Neurol (2015) 129: 495-508. doi:10.1016/B978-0-444-62630-1.00028-7

65. Starr A, Picton TW, Sininger Y, Hood LJ, Berlin CI. Auditory neuropathy. Brain (1996) 119(Pt 3):741-53. doi:10.1093/brain/119.3.741

66. Guyot JP, Sigrist A, Pelizzone M, Feigl GC, Kos MI. Eye movements in response to electrical stimulation of the lateral and superior ampullary nerves. Ann Otol Rhinol Laryngol (2011) 120(2):81-7. doi:10.1177/000348941112000202

67. Guyot JP, Sigrist A, Pelizzone M, Kos MI. Adaptation to steady-state electrical stimulation of the vestibular system in humans. Ann Otol Rhinol Laryngol (2011) 120(3):143-9. doi:10.1177/000348941112000301

68. van de Berg R, Guinand N, Guyot JP, Kingma H, Stokroos RJ. The modified ampullar approach for vestibular implant surgery: feasibility and its first application in a human with a long-term vestibular loss. Front Neurol (2012) 3:18. doi:10.3389/fneur.2012.00018

69. Dai C, Fridman GY, Della Santina CC. Effects of vestibular prosthesis electrode implantation and stimulation on hearing in rhesus monkeys. Hear Res (2011) 277(1-2):204-10. doi:10.1016/j.heares.2010.12.021 
70. Tang S, Melvin TA, Della Santina CC. Effects of semicircular canal electrode implantation on hearing in chinchillas. Acta Otolaryngol (2009) 129(5):481-6. doi:10.1080/00016480802252243

71. Della Santina CC, Migliaccio AA, Patel AH. A multichannel semicircular canal neural prosthesis using electrical stimulation to restore 3-d vestibular sensation. IEEE Trans Biomed Eng (2007) 54(6 Pt 1):1016-30. doi:10.1109/ TBME.2007.894629

72. Greco A, De Virgilio A, Gallo A, Fusconi M, Ruoppolo G, Turchetta R, et al. Idiopathic bilateral vestibulopathy: an autoimmune disease? Autoimmun Rev (2014) 13(10):1042-7. doi:10.1016/j.autrev.2014.08.035

73. Tan EM, Feltkamp TE, Smolen JS, Butcher B, Dawkins R, Fritzler MJ, et al. Range of antinuclear antibodies in "healthy" individuals. Arthritis Rheum (1997) 40(9):1601-11. doi:10.1002/art.1780400909

74. Tyrrell JS, Whinney DJ, Ukoumunne OC, Fleming LE, Osborne NJ. Prevalence, associated factors, and comorbid conditions for Meniere's disease. Ear Hear (2014) 35(4):e162-9. doi:10.1097/AUD.0000000000000041

75. Stanek G, Fingerle V, Hunfeld KP, Jaulhac B, Kaiser R, Krause A, et al. Lyme borreliosis: clinical case definitions for diagnosis and management in Europe. Clin Microbiol Infect (2011) 17(1):69-79. doi:10.1111/j.14690691.2010.03175.x

76. Lakos A, Igari Z, Solymosi N. Recent lesson from a clinical and seroepidemiological survey: low positive predictive value of Borrelia burgdorferi antibody testing in a high risk population. Adv Med Sci (2012) 57(2):356-63. doi:10.2478/v10039-012-0060-4

77. Lienhard R. Quelle est l'utilité de la sérologie de Lyme? Rev Med Suisse (2015) 11:1830-4.
78. Swart A, Ibañez-Justicia A, Buijs J, van Wieren SE, Hofmeester TR, Sprong H, et al. Predicting tick presence by environmental risk mapping. Front Public Health (2014) 2:238. doi:10.3389/fpubh.2014.00238

79. Giacani L, Lukehart SA. The endemic treponematoses. Clin Microbiol Rev (2014) 27(1):89-115. doi:10.1128/CMR.00070-13

80. Daey Ouwens IM, Koedijk FD, Fiolet AT, van Veen MG, van den Wijngaard KC, Verhoeven WM, et al. Neurosyphilis in the mixed urban-rural community of the Netherlands. Acta Neuropsychiatr (2014) 26(3):186-92. doi:10.1017/ neu. 2013.53

81. Zingler VC, Cnyrim C, Jahn K, Weintz E, Fernbacher J, Frenzel C, et al. Causative factors and epidemiology of bilateral vestibulopathy in 255 patients. Ann Neurol (2007) 61(6):524-32. doi:10.1002/ana.21105

Conflict of Interest Statement: The first author was supported through funding of MedEl.

The remaining coauthors declare that the research was conducted in the absence of any commercial or financial relationships that could be construed as a potential conflict of interest.

Copyright (c) 2016 Lucieer, Vonk, Guinand, Stokroos, Kingma and van de Berg. This is an open-access article distributed under the terms of the Creative Commons Attribution License (CC BY). The use, distribution or reproduction in other forums is permitted, provided the original author(s) or licensor are credited and that the original publication in this journal is cited, in accordance with accepted academic practice. No use, distribution or reproduction is permitted which does not comply with these terms. 